\title{
Effects of Temporary Dehydration on Growth of Green Needlegrass (Stipa viridula Trin.) Seedlings
}

\author{
TIMOTHY E. FULBRIGHT, A.M. WILSON, AND E.F. REDENTE
}

\begin{abstract}
Green needlegrass (Stipa viridula Trin.) has been variously rated as "extremely" to "fairly" drought tolerant. This study was conducted to determine the capacity of green needlegrass seedlings for emergence and root growth following temporary dehydration. Germinating seeds were exposed to dehydration treatments of $\mathbf{0}$, $-4,-10,-22$, and -37 megapascals (MPa) and then planted in soil-filled pots for a 10-day growth performance test. Exposure of germinating seeds to temporary dehydration treatments of -10 MPa and lower reduced subsequent seedling emergence. When the seminal primary root of germinating seeds was excised or injured by dehydration, seedlings developed up to 3 seminal lateral roots. No additional seminal roots were developed if the seminal primary root was undamaged. Germinating seeds of green needlegrass have relatively low tolerance to dehydration possibly as a result of a low latent potential for development of seminal lateral roots and low tolerance of the embryo and developing tissues to dehydration. Sites to be seeded and planting dates should be selected so as to insure adequate soil moisture for seedling development.
\end{abstract}

Green needlegrass (Stipa viridula Trin.) is a native, cool-season perennial bunchgrass that ranges from Alberta and Saskatchewan south to New Mexico and Arizona. Considerable use of this species has been made in range seedings and mined-land reclamation plantings in the northern Great Plains (Thornburg 1982).

Green needlegrass is referred to by several authors as a species that often occurs abundantly on sites such as swales and low lying areas that receive greater moisture than the surrounding area (North Dakota Agricultural Experiment Station 1941, Wright and Wright 1948, Donahue et al. 1956, Coupland and Johnson 1965). Vallentine (1971) rated green needlegrass as "fairly"drought tolerant. In contrast, Judd (1938) had reported that green needlegrass was found to be extremely drought resistant in studies in the northern Great Plains region. Seedlings of green needlegrass are resistant to drought according to Hoover et al. (1947) and Donahue et al. (1956).

Periods of high soil water potentials are often of short duration on semiarid rangelands and are separated by longer periods of much lower water potentials (Bokhari et al. 1975). Sala et al. (1981) reported that soil water potential at a depth of $5 \mathrm{~cm}$ decreased as low as -6 megapascals (MP a) during a 56-day drying cycle in north-central Colorado. Wilson (1973) measured soil water potentials as low as -600 bars $(-60 \mathrm{MP} \mathrm{a})$ at a depth of $2.5 \mathrm{~cm}$ in eastern Washington.

Seedling emergence and establishment on semiarid rangelands may depend on the ability of germinating seeds to tolerate extremely low water potentials and recover during subsequent periods of higher water potentials (Hassanyar and Wilson 1978).

\footnotetext{
Sc , I U, IR: Crops Research Laboratory, Fort Collins (deceased); and associate professor, Department of Range Science, Colorado State University, Fort Collins 80523. Fulbright is presently assistant professor, Department of Range and Wildlife Management, Texas A\&I University, Kingsville 78363.

Research was supported in part by the U.S. Department of Energy under Contract No. DE-AS02-76EV04018.

Manuscript accepted January 3, 1984.
}

The ability of plants to tolerate low water potential is related to the ability of their tissues to endure dehydration without undergoing destructive changes in cell structure and chemistry. The capacity for root growth following temporary dehydration of germinating seeds is particularly important for survival and initial growth of grass seedlings. Seminal lateral root primordia at the scutellar node of germinating seeds of crested wheatgrass (Agropyron desertorum (Fisch.) Schult.) and Russian wildrye (Elymus junceus Fisch.) remain quiescent for several days or weeks after planting, during which time they are less susceptible to dehydration injury than the apex of the actively growing seminal primary root. Because actively growing seminal primary roots may be killed by temporary dehydration prior to development of adventitious roots, growth and survival of seedlings may depend on the development of seminal lateral roots. However, many grass species lack the capacity to develop seminal lateral roots (Hoshikawa 1969). Those species that lack seminal lateral roots entirely are less tolerant of low soil water potentials (Hassanyar and Wilson 1978).

The objective of the present study was to determine the capacity of green needlegrass seedlings for emergence and root growth following temporary dehydration.

\section{Materials and Methods}

Accession SD-93 and Lodorm, a variety of green needlegrass with reduced seed dormancy, were the seed sources used in this study. Both were obtained from the USDA Soil Conservation Service Plant Materials Center at Bismarck, N. Dak. The study was conducted in 3 sequential steps: (1) germination of seeds under darkness in a seed germinator adjusted for a $20-15^{\circ} \mathrm{C}(16$ hours-8 hours) temperature regime, (2) exposure of germinating seeds to dehydration treatments, and (3) a 10-day seedling growth period.

Seeds were germinated in closed plastic boxes on top of substrata moistened with $100 \mathrm{ml}$ tap water. Dehydration treatments were imposed on germinating seeds when seminal primary roots reached $2-5 \mathrm{~mm}$ in length by placing them in constant humidity trays. Saturated solutions of $\mathrm{K}_{2} \mathrm{SO}_{4}, \mathrm{Na}_{2} \mathrm{SO}_{4}, \mathrm{KCl}$, and $\mathrm{NaCl}$ were used to maintain water potentials of $-4,-10,-22$, and $-37 \mathrm{MP}$ a, respectively, in the constant humidity trays (Hassanyar and Wilson 1978). Seeds were allowed to lose moisture to the constant humidity environment without touching the salt solution. Seeds were exposed 4 days to constant humidity environments of each water potential. Gravimetric determination of seed water content by Hassanyar and Wilson (1978) indicated that seeds of crested wheatgrass and Russian wildrye equilibrated with constant humidity environments in about 2 days. Seminal primary roots of half the seeds in each dehydration treatment and in the control treatment were excised to simulate conditions under which the seminal primary root was killed by drought.

Seeds were removed from the constant humidity trays following the 4-day dehydration treat ment and planted at a depth of $1.5 \mathrm{~cm}$ in plastic pots ( $15 \mathrm{~cm}$ diameter by $15 \mathrm{~cm}$ deep) filled with autoclaved sandy loam soil. Pots were placed in a growth chamber adjusted for a daily temperature and light regime of $25-20^{\circ} \mathrm{C}$ (15 hours with 
light-9 hours with dark). Light intensity was $450 \mu \mathrm{E} \mathrm{m}^{-2} \mathrm{sec}^{-1}$ of photosynthetically active radiation. Pots were watered when needed to maintain a soil water potential of approximately -0.03 MP a.

The seedlings that emerged were counted after a 10-day period in the growth chamber. Five of the seedlings that emerged in each pot were randomly selected and marked. Soil was then removed from the pots and washed from seedling roots with a fine spray of water. Data for (1) number of seminal roots, (2) number of adventitious roots, (3) length of longest seminal root, (4) length of longest adventitious root, and (5) shoot length per seedling were based on averages of the 5 marked seedlings in each pot.

A randomized complete-block experimental design with a factorial arrangement of treatments was used in the experiment. Five replications were conducted sequentially over time. Data were analyzed by analysis of variance, and Duncan's new multiple range test was used at the $\mathbf{0 . 0 5}$ level to identify significantly different means. All differences discussed in the following section were signifcant at $P<0.05$ unless otherwise stated.

\section{Results}

Increasing severity of dehydration of germinating seeds resulted in a corresponding decrease in subsequent seedling emergence (Table 1). Emergence of SD-93 and Lodorm seedlings was reduced by temporary dehydration treatments of $-10 \mathrm{MP}$ a and lower. No seedlings emerged following the -37 MP a dehydration treatment. Percent emergence of seedlings with seminal primary roots excised was not different from those with intact roots. There was no difference in percent emergence between the 2 seed sources.

Total number of roots per seedling decreased with each increase in severity of dehydration treatment (Table 2). Number of seminal roots per seedling did not differ between the 0 and -4 MP a treatments, but was reduced by the $-10 \mathrm{MP}$ a dehydration treatment. There was an interaction of seed sources with dehydration treatments for percent of seedlings with at least 1 seminal root. Lodorm seedlings had a higher percent of seedlings with at least 1 seminal root than did SD-93 for the -10 MP a treatment, but not for the 0 and $-4 \mathrm{MP}$ a treatments. Length of longest seminal root per seedling was reduced by the -4 and -10 MP a dehydration treatments.

Length of longest adventitious root per seedling was not affected by the dehydration treatments (Table 2). Number of adventitious roots per seedling was lower for the $-4 \mathrm{MP}$ a dehydration treatment than for the 0 and -10 MP a treatments.
Table 1. Effects of temporary dehydration (MP a) and seminal primary root excision of germinating seeds on subsequent percent emergence of 2 sources of green needlegrass.

\begin{tabular}{lcccc}
\hline & & \multicolumn{3}{c}{ Percent emergence for } \\
& Dehydration & \multicolumn{3}{c}{ seminal primary root treatment } \\
\cline { 3 - 5 } Source & treatment (MP a) & Nonexcised & Excised & Means \\
\hline SD-93 & 0 & 99.2 & 98.4 & $98.8 \mathrm{a} !$ \\
& -4 & 93.6 & 93.6 & $93.6 \mathrm{a}$ \\
& -10 & 87.2 & 79.2 & $83.2 \mathrm{~b}$ \\
& -22 & 0.8 & 0.0 & $0.4 \mathrm{~d}$ \\
& -37 & 0.0 & 0.0 & - \\
Lodorm & 0 & 99.2 & 98.4 & $98.8 \mathrm{a}$ \\
& -4 & 96.0 & 94.4 & $95.2 \mathrm{a}$ \\
& -10 & 76.0 & 64.8 & $70.4 \mathrm{c}$ \\
& -22 & 0.8 & 0.0 & $0.8 \mathrm{~d}$ \\
& -37 & 0.0 & 0.0 & -
\end{tabular}

Root treat-

ment means

$55.3 y$

$53.0 \mathrm{y}$

IMeans presented at the end of each column and at the end of each row that are followed by the same letter are not significantly different at the 0.05 level of probability according to Duncan's multiple range test.

Shoot length (length from the scutellar node to the tip of the longest leaf) per seedling decreased with each increase in severity of dehydration treatment (Table 2). Shoot length was the only seedling characteristic measured for which a significant difference existed between seed sources. Lodorm seedlings had longer shoots than did SD-93 seedlings.

Excision of the seminal primary root, when averaged over all dehydration treatments, did not affect total number of roots, number of seminal roots, or number of adventitious roots per seedling. Excision of the seminal primary root did reduce the length of seminal roots and shoots and increased the length of the longest adventitious roots. There was an interaction of root treatment with dehydration treatment for total number of roots, number of seminal roots, and shoot length per seedling. Seedlings with excised seminal primary roots had greater total number of roots, number of seminal roots, and shorter shoots for the control (0 MP a) treatment than seedlings with intact seminal primary roots. No difference existed between seedlings with the seminal primary root excised and those with the seminal primary roots intact for treatments other than the control.

Table 2. Effects of temporary dehydration (MP a) and seminal primary root excision of germinating seeds on subsequent root and shoot development (cm) of 2 sources of green needlegrass.

\begin{tabular}{|c|c|c|c|c|c|c|c|c|c|c|c|c|}
\hline \multirow{3}{*}{$\begin{array}{l}\text { Source and dehydration } \\
\text { treatment (MP a) }\end{array}$} & \multicolumn{12}{|c|}{ Seedling characteristic and seminal primary root treatment } \\
\hline & \multicolumn{2}{|c|}{$\begin{array}{l}\text { Total number of } \\
\text { roots }\end{array}$} & \multicolumn{2}{|c|}{$\begin{array}{c}\text { Number of } \\
\text { seminal roots }\end{array}$} & \multicolumn{2}{|c|}{$\begin{array}{c}\text { Length of longest } \\
\text { seminal root }\end{array}$} & \multicolumn{2}{|c|}{$\begin{array}{c}\begin{array}{c}\text { Number of } \\
\text { adventitious roots }\end{array} \\
\end{array}$} & \multicolumn{2}{|c|}{$\begin{array}{l}\text { Length of longest } \\
\text { adventitious root } \\
\end{array}$} & \multicolumn{2}{|c|}{ Shoot length } \\
\hline & $N^{1}$ & $\mathrm{E}^{2}$ & $\overline{\mathbf{N}}$ & $\mathbf{E}$ & $\bar{N}$ & $\mathbf{E}$ & $\bar{N}$ & $\mathrm{E}$ & $\mathbf{N}$ & $\mathbf{E}$ & $\overline{\mathbf{N}}$ & $\overline{\mathrm{E}}$ \\
\hline \multicolumn{13}{|l|}{$\overline{\text { SD-93 }}$} \\
\hline 0 & 1.7 & 2.1 & 1.0 & 1.4 & 11.9 & 10.1 & 0.7 & 0.7 & 1.3 & 3.3 & 12.3 & 10.3 \\
\hline-4 & 1.6 & 1.4 & 1.1 & 1.0 & 5.8 & 4.4 & 0.4 & 0.4 & 2.5 & 3.6 & 7.7 & 7.0 \\
\hline-10 & 1.3 & 1.2 & 0.5 & 0.5 & 6.6 & 5.0 & 0.8 & 0.7 & 2.3 & 3.4 & 6.8 & 6.4 \\
\hline \multicolumn{13}{|l|}{ Lodorm } \\
\hline 0 & 1.8 & 2.0 & 1.0 & 1.2 & 12.0 & 9.9 & 0.8 & 0.8 & 1.5 & 2.1 & 13.3 & 11.1 \\
\hline-4 & 1.5 & 1.2 & 1.1 & 1.1 & 8.4 & 7.4 & 0.4 & 0.2 & 1.0 & 5.2 & 10.1 & 9.1 \\
\hline-10 & 1.3 & 1.2 & 0.8 & 0.6 & 4.1 & 5.1 & 0.4 & 0.6 & 1.2 & 2.2 & 7.3 & 7.4 \\
\hline Root treatment means & $1.5 y^{3}$ & $1.5 \mathrm{y}$ & $0.9 \mathrm{y}$ & $1.0 \mathrm{y}$ & $8.2 \mathrm{y}$ & $7.0 \mathrm{z}$ & $0.6 y$ & $0.6 \mathrm{y}$ & $1.6 \mathrm{y}$ & $3.3 z$ & $9.6 y$ & $8.5 z$ \\
\hline
\end{tabular}

IN refers to seminal primary root not excised.

2E refers to seminal primary root excised.

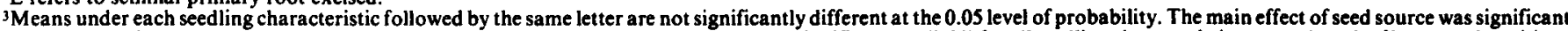

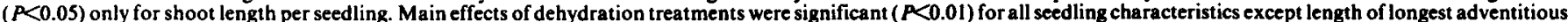

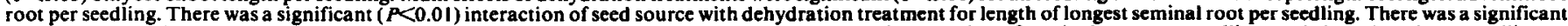

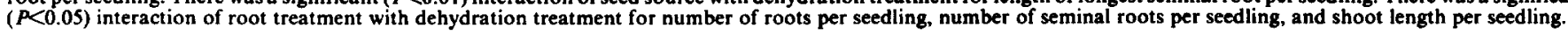


Seedlings in the nonexcised control treatment developed only the seminal primary root and often an adventitious root during the 10-day growth period. Seedlings in the control treatment with the seminal primary root excised developed up to 3 seminal lateral roots (average of 1.3 per seedling) and often 1 (rarely 2 ) adventitious root. Adventitious roots developed from the coleoptilar node of all seedlings (with and without seminal primary root excision) in the control treatment. In the $-10 \mathrm{MP}$ a dehydration treatment, adventitious roots developed from either the coleoptilar node or the subcoleoptile internode.

\section{Discussion}

Germinating seeds of green needlegrass are apparently less tolerant of temporary dehydration than germinating seeds of crested wheatgrass and Russian wildrye. Emergence of green needlegrass seedlings following the $-22 \mathrm{MP}$ a dehydration treatment was $0.6 \%$ compared to $88 \%$ for Russian wildrye seedlings under the same experimental conditions (T.E. Fulbright and A.M. Wilson, unpublished data). Temporary dehydration treatments of $-10 \mathrm{MP}$ a and lower reduced the percent of green needlegrass seedlings that developed a seminal root. In comparison, Hassanyar and Wilson (1978) reported that the percent of crested wheatgrass and Russian wildrye seedlings that developed a seminal root was reduced by temporary dehydration treatments of -91 and $-37 \mathrm{MP}$ a and lower, respectively.

Development of scminal lateral roots by green needlegrass during early seedling growth is apparently an adaptation that provides an alternate source of water and nutrients if the seminal primary root is killed or injured by environmental stress. Development of adventitious roots from the subcoleoptile internode is apparently also a response to environmental stress. If seedings are not subjected to environmental stress during the early stages of growth, they develop only the seminal primary root from the embryo and adventitious roots from the nodes of shoots.

The number of adventitious roots per seedling was greater following the $-10 \mathrm{MP}$ a treatment than following the $-4 \mathrm{MP}$ a dehydration treatment. That result was not expected because root growth generally decreases with increasing severity of the dehyd ration treatment. The increase in number of adventitious roots per seedling at $-10 \mathrm{MP}$ a resulted from the sampling procedures used in the study. Growth characteristics were measured for emerged seedlings only. The $-10 \mathrm{MP}$ a dehydration treatment was severe enough to kill the seminal primary root of many seedlings ( $45 \%$ of the seedlings in the $-10 \mathrm{MP}$ a treatment lacked seminal roots entirely). Generally seedlings did not emerge unless they had developed at least 1 seminal root or 1 adventitious root. Therefore, when the morphology of emerged seedlings only was investigated, there was an apparent increase in number of adventitious roots per seedling at $-10 \mathrm{MP}$ a as compared with $-4 \mathrm{MP}$ a.

Apparent discrepancies in the literature regarding the drought tolerance of green needlegrass may be partly explained by the results of this study. Lack of tolerance of germinating seeds to temporary dehydration may cause green needlegrass to be abundant only on more mesic sites. Once the adventitious root system is established, the plant probably exhibits the drought tolerance noted by some authors.

Results of this study suggested that lack of tolerance to dehydration of germinating seeds of green needlegrass may result from (1) a low latent potential for development of seminal lateral roots and (2) low tolerance of the embryo and of developing tissues to dehydration of germinating seeds should be taken into consideration when using green needlegrass in revegetation. Sites to be seeded and planting dates should be selected so as to insure adequate soil moisture for germination and seedling development.

low latent potential for development of seminal lateral roots and (2) low tolerance of the embryo and of developing tissues to dehydration. The low tolerance to dehydration of germinating seeds should be taken into consideration when using green needlegrass in revegetation. Sites to be seeded and planting dates should be selected so as to insure adequate soil moisture for germination and seedling development.

\section{Literature Cited}

Bokhari, U.G., J.S. Singh, and F.M.Smith. 1975. Influence of temperature regimes and water stress on the germination of three range grasses and its possible ecological significance to a shortgrass prairie. J. Appl. Ecol. 12:153-163.

Coupland, R.T., and R.E. Johnson. 1965. Rooting characteristics of native grassland species in Saskatchewan. J. Ecology 53:475-507.

Donahue, R.L., E.F. Evans, and L.I. Jones. 1956. The range and pasture book. Prentice-Hall, Inc., Englewood Cliffs.

Hassanyar, A.S., and A.M. Wilson. 1978. Drought tolerance of seminal lateral root apices in crested wheatgrass and Russian wildrye. J. Range Manage. 31:254-258.

Hoover, M.M., J.E. Smith, Jr., A.E. Ferber, and D.R. Cornelius. 1947. Seed for regrassing Great Plains areas. U.S. Dep. Agr. Farmers Bull. No. 1985.

Hoshikawa, K. 1969. Underground organs of the seedlings and the systematics of the gramineae. Bot. Gaz. 130:192-203.

Judd, B.I. 1938. Green needlegrass, Stipa viridula, for erosion control. J. Amer. Soc. Agron. 30:160-161.

North Dakota Agricultural Experiment Station. 1941. Grass. N. Dak. Agr. Exp. Sta. Bull. 300.

Sala, O.E., W.K. Lauenroth, W.J. Parton, and M.J. Trlica. 1981. Water status of soil and vegetation in a shortgrass steppe. Oecologia (Berl.) 48:327-331.

Thornburg, A.A. 1982. Plant materials for use on surface-mine lands in arid and semiarid regions. USDA, Soil Conserv. Serv. SCSTP-175.

Vallentine, J.F. 1971. Range development and improvements. Brigham Young University Press, Provo, Utah.

Wilson, A.M. 1973. Responses of crested wheatgrass seeds to environment. J. Range Manage. 26:43-46.

Wright, J.C., and E.A. Wright. 1948. Grassland types of south central Montana. Ecology 29:449-460. 